EXTENDED REPORT

\title{
Miscarriage but not fecundity is associated with progression of joint destruction in rheumatoid arthritis
}

\author{
F M van Dunné, L R Lard, D Rook, F M Helmerhorst, T W J Huizinga
}

Ann Rheum Dis 2004;63:956-960. doi: 10.1136/ard.2002.004291

See end of article for authors' affiliations

Correspondence to:

Dr Frans $M$ Helmerhorst,

PO Box 9600, 2300 RC

Leiden, Netherlands;

f.m.helmerhorst@lumc.nl

Accepted

28 September 2003

\begin{abstract}
Objective: To determine whether reproductive history before disease onset is associated with severity of joint destruction in rheumatoid arthritis.

Methods: A special early arthritis clinic (EAC) was established at the department of rheumatology of Leiden University Medical Centre. General practitioners were encouraged to refer patients with joint complaints to this clinic, where the diagnosis of rheumatoid arthritis was made by a rheumatologist. In all, 113 female patients with definite rheumatoid arthritis were included in this study. A structured questionnaire was administered and joint damage was assessed by sequential $x$ rays of the hands and feet, using the modified Sharp score.

Results: The length of time of unprotected intercourse until first pregnancy (fecundity) was comparable with data from earlier studies, with $16 \%$ of the patients reporting a time to first pregnancy of more than 12 months. Fecundity did not reflect the extent of joint damage over time. The miscarriage rate was $15 \%$ per pregnancy, comparable to population figures (12-15\%). A significant increase in joint damage over a two year follow up was found in patients with rheumatoid arthritis who had experienced at least one miscarriage compared with those who had never had a miscarriage (mean modified Sharp scores at 2 years, 24 (95\% confidence interval, 15 to 32 ) and 16 (10 to 23 ), respectively; $p<0.05)$. At baseline, the Sharp scores were similar in the two subgroups.

Conclusions: Miscarriage before disease onset but not fecundity is associated with the progression of joint damage in rheumatoid arthritis.
\end{abstract}

$\mathrm{T}$ he balance between $\mathrm{T}$ helper-1 (Thl) and $\mathrm{T}$ helper-2 (Th2) cell production regulates various inflammatory responses in humans. Inborn differences in the Thl/Th2 balance may be present in patients with rheumatoid arthritis, with more prominent Thl activity. ${ }^{1}$ The Thl phenotype is likely to be present from birth onwards and may protect against lethal infectious diseases throughout life. ${ }^{2}$ Increased Th2 activity is thought to be beneficial to the course of rheumatoid arthritis, as a lower incidence of atopic disorders-which are known to be associated with Th2 predominance-has been reported in affected individuals. ${ }^{3}$ Furthermore, reduced disease severity was found in patients whose atopy began before they developed rheumatoid arthritis, suggesting an innate Th2 responsiveness. ${ }^{4}$

A Th2 immune response is likely to be important for a successful pregnancy. ${ }^{5}$ This predominant Th2 response could explain the ameliorating effect on established rheumatoid arthritis during pregnancy. ${ }^{6}$ Moreover, the Thl phenotype may result in aberrant characteristics in the reproductive history before the onset of rheumatoid arthritis. This could be expressed in decreased fertility (ability to become pregnant), decreased fecundity (time to achieve pregnancy from the start of unprotected intercourse), and an increased miscarriage rate.

In 1965 Kay and Bach $^{7}$ reported reduced fertility in premenopausal patients with rheumatoid arthritis before and after the onset of their disease. However, in a study reported in 1989, subfertility (no pregnancy after two years of unprotected intercourse) did not occur more frequently in 117 rheumatoid arthritis patients than in a control group. ${ }^{8}$ Fertility in parous women does not seem to be reduced, as smaller family size has not been observed in patients with rheumatoid arthritis. ${ }^{10}$ Nulliparity has been reported to be associated with rheumatoid arthritis, with a consistent odds ratio of around 2 for rheumatoid arthritis in nulliparous women compared with parous women. ${ }^{11}$ However, whether nulliparity is a result of infertility, miscarriages, or the choice to remain childless is not clear.

Decreased fecundity (time to achieve pregnancy from the start of unprotected intercourse more than 12 months) before disease onset was reported in 1993 in a study of 259 patients with rheumatoid arthritis compared with 1258 healthy controls. ${ }^{12}$ However, this was not confirmed in a further study in 1999, where fecundity in 167 rheumatoid patients was comparable to that of 105 neighbourhood controls. ${ }^{13}$ Thus the impact of rheumatoid arthritis on fertility and fecundity before disease onset has not been fully elucidated.

Miscarriage does not seem to occur more often in women who go on to develop rheumatoid arthritis than in controls from the normal population..$^{81013-16}$ One American study, however, did report a significantly larger number of miscarriages in rheumatoid patients, though they were compared with patients with osteoarthritis and other musculoskeletal conditions rather than with normal population controls. ${ }^{17}$

As many variables may affect human reproductionphysiological, behavioural, demographic, and environmental $^{18}$-decreased fertility, fecundity, and miscarriage rate in patients with rheumatoid arthritis could reflect inborn factors linked to rheumatoid arthritis even before disease onset. An inborn Thl phenotype might influence both reproductive performance and rheumatoid arthritis severity at different ages in life. The severity of rheumatoid arthritis has not so far been investigated in relation to reproductive success.

Our aim in the present study was to investigate whether a less favourable reproductive outcome is associated with more severe rheumatoid arthritis. We studied the reproductive history of women with newly diagnosed rheumatoid arthritis in relation to the rate of joint destruction. 
Table 1 Demographic and reproductive characteristics of the patients with rheumatoid arthritis at baseline

\begin{tabular}{ll}
\hline Variables & RA patients \\
\hline Number of subjects & 113 \\
Ever pregnant (\%) & $110(97)$ \\
Age at interview (years) & $59(15)$ \\
Age at first visit (years) & $55(15)$ \\
Duration of complaints at first visit (days) & $200(160)$ \\
DMARD use (\%) & $99(88)$ \\
Interval until start of first DMARD (days) & $92(144)$ \\
Rheumatoid factor positivity (\%) & $61(54)$ \\
Pregnant before rheumatoid arthritis onset (\%) & $106(94)$ \\
\hline Values are mean (SD) or $\mathrm{n}(\%)$. & \\
DMARD, disease modifying antirheumatic drug; RA, rheumatoid arthritis.
\end{tabular}

\section{METHODS \\ Patients}

In 1993, a special early arthritis clinic (EAC) was started at the department of rheumatology of the Leiden University Medical Centre, the only centre for rheumatic patients in Leiden and its environs, with 300000 inhabitants. General practitioners (GPs) were motivated to refer patients if at least two of the following features were present: joint pain, joint swelling, and reduction in joint mobility. All patients referred to the special EAC by the GPs were seen within two weeks. The patients were followed in the EAC if arthritis was confirmed by a rheumatologist; if the history of symptoms was less than two years; and if the patients had not been visiting a rheumatologist elsewhere for the same problem (to rule out second opinions). Subsequently, the diagnosis "definite rheumatoid arthritis" was made according to the 1987 American College of Rheumatology (ACR) criteria ${ }^{19}$ but without the requirement of a six weeks observation period of arthritis by a rheumatologist. ${ }^{20}$

From 1993 to 1999, 644 consecutive patients were included in the EAC with a minimum follow up of one year, of whom 379 were women. Of these 379,190 were excluded because they had did not have definite rheumatoid arthritis. Of the rest, eight died before the study (mean age 74 years), 13 were lost to follow up (mean age 53 years), 22 refused to participate after informed consent (mean age 67 years), one was excluded because of language difficulties (aged 51 years), and 32 reported have never having had unprotected intercourse to achieve a desired pregnancy (mean age 43 years). This left 113 patients with definite rheumatoid arthritis and a history of unprotected intercourse.

\section{Reproductive history questionnaire}

All 113 women were interviewed with respect to their reproductive history. The interview included questions on the number of pregnancies, the interval between the start of unprotected intercourse and the first pregnancy, the number of miscarriages, and the patient's age during pregnancies. Time to pregnancy (fecundity) was defined as the self reported time between the start of unprotected intercourse and the occurrence of pregnancy. Fecundity was calculated for pregnancies that ended in the birth of a child as well as for pregnancies ending in miscarriage. Miscarriage was defined as the loss of a pregnancy before 20 weeks. The same person (DR), who was blinded to the diagnosis, interviewed all the patients.

\section{Assessment of outcome}

The primary outcome was radiographic joint damage, measured using the modified Sharp score. ${ }^{21}$ Radiographs of the hands and feet were taken at the time of diagnosis, at six months, at one year, and at two years. The radiographs were scored in random order by an experienced rheumatologist blind to the clinical data and not aware of the study questions. The intraclass correlation coefficient for the radiographic interpretation by the assessor was 0.95 .

Secondary outcomes were a modified disease activity score $^{22}$ and the $\mathrm{C}$ reactive protein concentration at study entry and during follow up. The disease activity score (DAS) was calculated as:

$$
\begin{aligned}
& 0.53^{*}(\text { Ritchie score })^{1 / 2}+0.065 * \text { (number of swollen joints) } \\
& +033^{*} \ln \text { ESR }+0.224
\end{aligned}
$$

where ESR is the erythrocyte sedimentation rate $(\mathrm{mm} / \mathrm{h})$.

All joints were assessed as in the Ritchie articular index except for the acromioclavicular, subtalar, and midtarsal joints. For the swollen joint index the metacarpophalangeal, proximal interphalangeal, and metatarsophalangeal joints were scored as one unit.

\section{Statistical analysis}

The statistical package for social science (SPSS) was used for analysis of the results. The subgroups were tested using Pearson's $\chi^{2}$ test and the Mann-Whitney U test, as appropriate. Differences between the Sharp scores of the subgroups were tested with the Mann-Whitney U test. All tests were two tailed, and a probability (p) value of less than 0.05 was considered significant.

\section{RESULTS \\ Demographic and reproductive characteristics}

We recruited 113 female patients with rheumatoid arthritis to the study. The general characteristics of the patients are shown in table 1.

\section{Fertility}

Three patients (3\%) had not achieved a desired pregnancy. They were 29, 30, and 37 years old at interview and had all been trying to conceive for more than a year. They had not yet had any fertility treatment.

\section{Fecundity in relation to joint damage in rheumatoid arthritis}

Of the 110 patients who had been pregnant at least once, 70 $(62 \%)$ had reported that the time to their first pregnancy had been three months or less, 20 (18\%) reported that it had been

\begin{tabular}{|c|c|c|c|c|}
\hline Fecundity & $\begin{array}{l}\text { Sharp at } \\
\text { baseline }\end{array}$ & $\begin{array}{l}\text { Sharp at } \\
6 \text { months }\end{array}$ & $\begin{array}{l}\text { Sharp at } \\
12 \text { months }\end{array}$ & $\begin{array}{l}\text { Sharp at } \\
24 \text { months }\end{array}$ \\
\hline $\begin{array}{l}<3 \text { months }(n=70) \\
4-12 \text { months }(n=20) \\
>12 \text { months }(n=18)\end{array}$ & $\begin{array}{l}5.0(1.3) \\
2.2(0.9) \\
8.3(6.1)\end{array}$ & $\begin{array}{l}9.7(2.2) \\
3.8(1.3) \\
10.1(5.3)\end{array}$ & $\begin{array}{l}15.7(2.7) \\
5.4(1.3) \\
21.3(10.2)\end{array}$ & $\begin{array}{l}19.3(3.3) \\
11.9(3.2) \\
25.0(8.2)\end{array}$ \\
\hline
\end{tabular}
between four and 12 months, and $18(16 \%)$ reported that it 


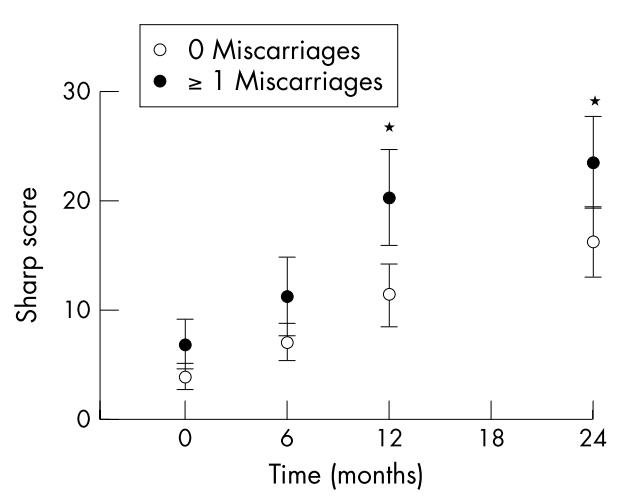

Figure 1 Mean Sharp scores over time as a measure of joint damage in patients with rheumatoid arthritis according to their history of miscarriages ( ${ }^{*} p<0.05$ for the two subgroups). Error bars $=$ SEM.

had been more than 12 months. Two patients could not recall the time it took to achieve their first pregnancy. When divided in groups according to their history of fecundity, the patient characteristics were similar in all subgroups (data not shown). Measuring the joint damage over time using the modified Sharp score $(0,6,12$, and 24 months), there was no difference in the development of joint destruction in these three fecundity groups (table 2). When the group with a fecundity of $\leqslant 12$ months was compared with the group with a fecundity of $>12$ months, the mean Sharp score was comparable: at baseline, mean Sharp score $=4$ (95\% confidence interval (CI), 2 to 7 ) and 8 ( 5 to 21 ), respectively; at two years, mean Sharp score $=17$ (12 to 23) and 25 (7 to 43).

\section{Miscarriage in relation to disease severity: joint damage}

The miscarriage rate per pregnancy was $15 \%$ for the 110 patients with at least one previous pregnancy. The patient characteristics were comparable when these patients were divided according to their miscarriage history (table 3 ). The patient group with at least one miscarriage understandably experienced significantly more pregnancies to achieve a similar mean number of children (table 3 ). The modified Sharp score over a two year period was analysed $(0,6,12$, and 24 months) for each of the subgroups. A significant increase in joint destruction was found in women who had experienced at least one miscarriage in the past compared with those who did not have any miscarriages in the past (fig 1). At study entry, the mean Sharp score was 4 (95\% CI, l to 7 ) for the group without miscarriages and 7 (2 to 11) for the group with at least one miscarriage. The group without miscarriages progressed to a mean Sharp score of 16 (10 to 23 ) after two years of follow up, while the group with at least one miscarriage progressed to a mean Sharp score of 24 ( 15 to 32) $(\mathrm{p}<0.05 v$ the group without miscarriages). The outcome was similar when patients were excluded who had their first pregnancy after the onset of the disease $(n=4)$. A multivariate analysis was undertaken for prognostic factors such as age at onset, duration of symptoms before referral, rheumatoid factor positivity, and shared epitopes; this did not alter the outcome significantly.

\section{Miscarriage in relation to disease severity: activity outcome}

The mean DAS at baseline was 3.4 (95\% CI, 3.2 to 3.6) for the group without miscarriages, and 3.7 (3.4 to 4.1 ) for the group with at least one miscarriage $(\mathrm{p}<0.05)$ (fig 2$)$. The DAS improved in both groups and was comparable for the two subgroups for the duration of the follow up period of two years (2.5 (2.2 to 2.8) and 2.4 (1.9 to 2.9), respectively, at two years). At baseline the mean $\mathrm{C}$ reactive protein concentration (fig 3) was lower in the group without miscarriages (24 (17 to 30$) \mathrm{mg} / \mathrm{l}$ ) than in the group with at least one miscarriage (4l (27 to 55) mg/l) $(\mathrm{p}<0.05)$. During the two years follow up the $C$ reactive protein values were similar in the two groups, at 15 (8 to 22 ) and 18 (5 to 31 ) mg/l, respectively.

\section{DISCUSSION}

In this study, we observed that a high rate of joint damage in patients with rheumatoid arthritis was associated with a history of miscarriage but not with fecundity. To our knowledge this is the first study in which disease severity in rheumatoid arthritis, as measured by the rate of joint destruction, has been related to reproductive history.

The miscarriage rate per pregnancy in our study was 15\%, which is consistent with the miscarriage rate of $12-15 \%$ in the normal population. ${ }^{23}$ In published reports, the miscarriage rate has been comparable between rheumatoid arthritis patients and healthy population control groups. ${ }^{7}$ 10 $^{13-16}$ However, we did find a relation between miscarriage and the severity of rheumatoid arthritis. The history of at least one miscarriage increased the rate of joint damage in our rheumatoid patients twofold over a two year follow up period. Two years is a relatively short time to assess outcome,

Table 3 Demographic and reproductive characteristics of patients with rheumatoid arthritis with at least one pregnancy $(n=110)$ at baseline, divided by history of miscarriages

\begin{tabular}{lll}
\hline & $\begin{array}{l}\text { No miscarriages } \\
(\mathbf{n}=74)\end{array}$ & $\begin{array}{l}\text { One or more miscarriages } \\
(\mathbf{n}=36)\end{array}$ \\
\hline Age at interview (years) & $59(14)$ & $62(15)$ \\
Age at first visit (years) & $55(14)$ & $58(15)$ \\
Duration of complaints at first visit (days) & $186(149)$ & $236(181)$ \\
DMARD use (\%) & $63(85)$ & $33(92)$ \\
Interval to start of first DMARD (days) & $84(107)$ & $109,3(203)$ \\
Rheumatoid factor positivity (\%) & $38(55)$ & $23(66)$ \\
Pregnant before rheumatoid arthritis onset (\%) & $72(97)$ & $34(94)$ \\
Age at first pregnancy (years) & $26(5)$ & $27(5)$ \\
Number of pregnancies & $2.3(1.1)$ & $4.1(1.9)^{*}$ \\
Number of children & $2.3(1.1)$ & $2.8(1.9)$ \\
Marital status, currently married (\%) & $59(80)$ & $26(72)$ \\
Ever smoked (\%) & $20(27)$ & $6(17)$ \\
Education: college or university (\%) & $18(24)$ & $9(25)$ \\
\hline Values are mean (SD) or $n$ (\%). & & \\
* $\mathrm{p}<0.05$ v group without miscarriages. & & \\
DMARD, disease modifying antirheumatic drug. & & \\
\hline
\end{tabular}




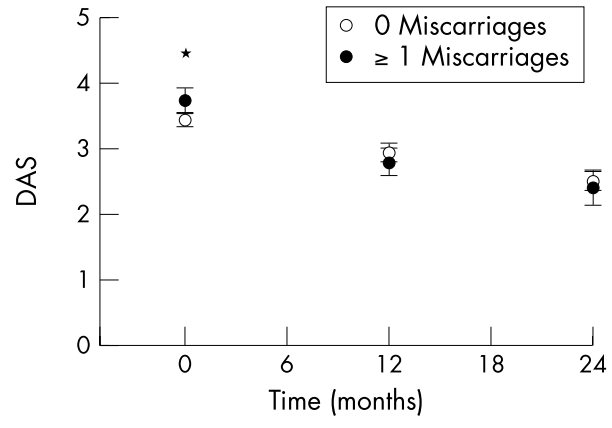

Figure 2 Mean disease activity scores (DAS) during follow up in the patients with rheumatoid arthritis according to their history of miscarriages ( ${ }^{*} p<0.05$ for the two subgroups). Error bars $=$ SEM.

and a longer follow up would have been preferable, although radiological damage is known to occur early in rheumatoid arthritis. The association between miscarriages and the severity of joint damage in rheumatoid arthritis could not be explained by a significant difference in the duration of complaints before entry to the study, or by a difference in treatment strategy between the two groups. At baseline the group with at least one miscarriage had a significantly higher $\mathrm{C}$ reactive protein concentration and disease activity score than the group without a miscarriage, indicating that this subgroup had more severe symptoms at the first visit. At follow up, however, both $\mathrm{C}$ reactive protein and DAS decreased to similar levels in the two subgroups, indicating that the rheumatoid symptoms were treated sufficiently in both. Radiographic joint damage was the only measure that was similar at baseline in the two groups but which progressed significantly in the group with at least one miscarriage at the one and two years follow up. Patients with a history of miscarriages may represent a group with more severe disease activity, leading to more rapid progression of joint damage and possibly reflecting the Thl phenotype in this subgroup.

A cytokine mechanism could explain the difference in progressive joint damage in the two subgroups. An inborn predominance of the Thl response in the miscarriage subgroup may be harmful both to the disease process in the joint and to the physiological immunological changes during pregnancy, even before clinical disease manifestations occur. A predominant Th2 response is necessary for normal pregnancy. This predominance is less clear in pregnancies undergoing spontaneous abortions. ${ }^{24}$ The probability of normal fecundity increased more than 10-fold when the innate cytokine profile was characterised by Th2 responsiveness, compared with the profile of women with recurrent

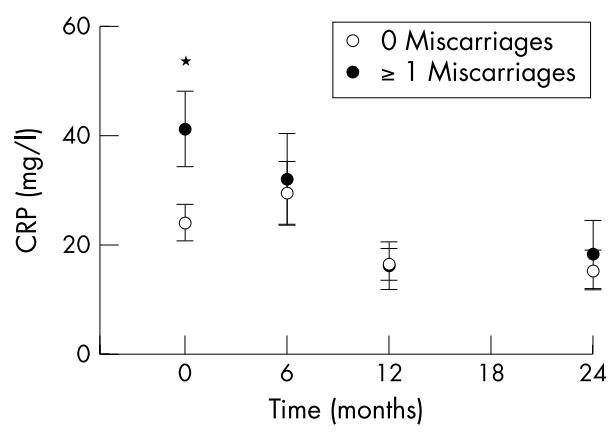

Figure 3 Mean $\mathrm{C}$ reactive protein concentrations during follow up in the patients with rheumatoid arthritis according to their history of miscarriages $\left({ }^{*} p<0.05\right.$ for the two subgroups). Error bars $=$ SEM. abortion, whose cytokine profile was characterised by low Th2 and high Thl responsiveness. ${ }^{25}$ A more pronounced inborn Thl profile may characterise women who experience miscarriage, and if these women develop rheumatoid arthritis it is conceivable that their arthritis is characterised by more extensive joint destruction.

A decreased fertility rate is difficult to assess, as the ability to have a child is dependent on numerous factors, related to both male and female characteristics. In our study, 16\% of the patients with rheumatoid arthritis reported a time to pregnancy of more than 12 months. Fecundity in the normal population is reported to be $58-65 \%$ for the first three months, $85-90 \%$ for the first 12 months, and the remaining $10-15 \%$ have a time to pregnancy of more than a year. ${ }^{26} 27$ Decreased fecundity (a prolonged interval until a desired pregnancy) in rheumatoid patients seems plausible. ${ }^{12}{ }^{28}$ The $16 \%$ figure reported in our study is comparable; however, a population control group was not available. A probable decreased fecundity rate in rheumatoid arthritis may represent the effect of an inborn characteristic in these patients. However, a correlation with disease severity and joint damage could not be demonstrated in this study, possibly because of the small numbers.

In the present retrospective study, reproductive data were collected through interview. Time to pregnancy, measured in months, is known to be a sensitive measure of the biological fertility of a couple. ${ }^{26}$ Recall bias is possible; however, validation studies of fecundity and miscarriages have shown good agreement between long term recall (>15 years) of personal reproductive history collected through personal interview, telephone interview, or written questionnaire and medical data. ${ }^{29}{ }^{30}$ Though our subjects comprised a specialised group studied over a different time period, we have presumed that these validation studies are applicable to our study.

\section{Conclusions}

Our study shows that miscarriage rates before disease onset in patients with rheumatoid arthritis are comparable with those reported in the normal population, but after the disease has developed, a history of miscarriage may lead to a greater rate of joint destruction. Fecundity seems to be decreased in rheumatoid arthritis before disease onset; however, we were unable to prove a correlation between fecundity and joint damage, possibly because of the small numbers. Our results could indicate that the phenotype of joint destruction is associated with the phenotype of reported miscarriages, suggesting that there are common genetic risk factors for each of these two traits, possibly acting through the innate Th1/Th2 phenotype.

\section{ACKNOWLEDGEMENTS}

We gratefully acknowledge Dr B J A Mertens for statistical advice.

\section{Authors' affiliations}

L R Lard, D Rook, T W J Huizinga, Department of Rheumatology, Leiden University Medical Centre, Leiden, Netherlands

F M van Dunné, F M Helmerhorst, Department of Gynaecology and Reproductive Medicine, Leiden University Medical Centre

\section{REFERENCES}

1 van Roon JA, Bijlsma JW. Th2 mediated regulation in RA and the spondyloarthropathies. Ann Rheum Dis 2002;61:951-4.

2 Westendorp RG, Langermans JA, Huizinga TW, Verweij CL, Sturk A. Genetic influence on cytokine production in meningococcal disease. Lancet 1997;349:1912-13.

3 Reckner OA, Skogh T, Wingren G. Comorbidity and lifestyle, reproductive factors, and environmental exposures associated with rheumatoid arthritis. Ann Rheum Dis 2001;60:934-9.

4 Rudwaleit M, Andermann B, Alten R, Sorensen H, Listing J, Zink A, et al. Atopic disorders in ankylosing spondylitis and rheumatoid arthritis. Ann Rheum Dis 2002;61:968-74. 
5 Wegmann TG, Lin H, Guilbert L, Mosmann TR. Bidirectional cytokine interactions in the maternal-fetal relationship: is successful pregnancy a TH2 phenomenon? Immunol Today 1993;14:353-6.

6 Ostensen M, Villiger PM. Immunology of pregnancy-pregnancy as a remission inducing agent in rheumatoid arthritis. Transpl Immunol 2002;9:155-60.

7 Kay A, Bach F. Subfertility before and after the development of rheumatoid arthritis in women. Ann Rheum Dis 1965;24:169-73.

8 McHugh NJ, Reilly PA, McHugh LA. Pregnancy outcome and autoantibodies in connective tissue disease. J Rheumatol 1989:16:42-6.

9 Hazes JM, Dijkmans BA, Vandenbroucke JP, de Vries RR, Cats A. Pregnancy and the risk of developing rheumatoid arthritis. Arthritis Rheum 1990;33:1770-5.

10 Nelson JL, Voigt LF, Koepsell TD, Dugowson CE, Daling JR. Pregnancy outcome in women with rheumatoid arthritis before disease onset. J Rheumatol 1992;19:18-21.

11 Silman AJ. Parity status and the development of rheumatoid arthritis. Am J Reprod Immunol 1992;28:228-30.

12 Nelson JL, Koepsell TD, Dugowson CE, Voigt LF, Daling JR, Hansen JA Fecundity before disease onset in women with rheumatoid arthritis. Arthritis Rheum 1993;36:7-14

13 Steen VD, Medsger TA. Fertility and pregnancy outcome in women with systemic sclerosis. Arthritis Rheum 1999;42:763-8.

14 Spector TD, Silman AJ. Is poor pregnancy outcome a risk factor in rheumatoid arthritis? Ann Rheum Dis 1990;49:12-14.

15 Silman AJ, Roman E, Beral V, Brown A. Adverse reproductive outcomes in women who subsequently develop rheumatoid arthritis. Ann Rheum Dis 1988:47:979-81.

16 Siamopoulou-Mavridou A, Manoussakis MN, Mavridis AK, Moutsopoulos HM. Outcome of pregnancy in patients with autoimmune rheumatic disease before the disease onset. Ann Rheum Dis 1988;47:982-7.

17 Kaplan D. Fetal wastage in patients with rheumatoid arthritis. J Rheumatol 1986;13:875-7.

18 ESHRE Capri Workshop Group. Social determinants of human reproduction. Hum Reprod 2001;16:1518-26.
19 Arnett FC, Edworthy SM, Bloch DA, McShane DJ, Fries JF, Cooper NS, et al. The American Rheumatism Association 1987 revised criteria for the classification of rheumatoid arthritis. Arthritis Rheum 1988;31:315-24.

20 van der Horst-Bruinsma IE, Speyer I, Visser H, Breedveld FC, Hazes JM. Diagnosis and course of early-onset arthritis: results of a special early arthritis clinic compared to routine patient care. Br J Rheumatol 1998;37:1084-8.

21 van der Heijde DM. How to read radiographs according to the Sharp/van der Heijde method. J Rheumatol 2000;27:261-3.

22 van der Heijde DM, van 't Hof MA, van Riel PL, Theunisse LA, Lubberts EW, van Leeuwen $M A$, et al. Judging disease activity in clinical practice in rheumatoid arthritis: first step in the development of a disease activity score. Ann Rheum Dis 1990;49:916-20.

23 Zinaman MJ, Clegg ED, Brown CC, O'Connor J, Selevan SG. Estimates of human fertility and pregnancy loss. Fertil Steril 1996;65:503-9.

24 Marzi M, Vigano A, Trabattoni D, Villa ML, Salvaggio A, Clerici E, et al. Characterization of type 1 and type 2 cytokine production profile in physiologic and pathologic human pregnancy. Clin Exp Immunol 1996; 106:127-33

25 Westendorp RG, van Dunne FM, Kirkwood TB, Helmerhorst FM, Huizinga TW Optimizing human fertility and survival. Nat Med 2001;7:873.

26 Joffe M. Time trends in biological fertility in Britain. Lancet 2000;355:1961-5.

27 Jensen TK, Slama R, Ducot B, Suominen J, Cawood EH, Andersen AG, et al. Regional differences in waiting time to pregnancy among fertile couples from four European cities. Hum Reprod 2001;16:2697-704.

28 Skomsvoll JF, Ostensen M, Baste V, Irgens LM. Number of births, interpregnancy interval, and subsequent pregnancy rate after a diagnosis of inflammatory rheumatic disease in Norwegian women. J Rheumatol 2001;28:2310-14.

29 Tilley BC, Barnes AB, Bergstralh E, Labarthe D, Noller KL, Colton T, et al. A comparison of pregnancy history recall and medical records. Implications for retrospective studies. Am J Epidemiol 1985;121:269-81.

30 Joffe M, Villard L, Li Z, Plowman R, Vessey M. Long-term recall of time-topregnancy. Fertil Steril 1993;60:99-104.

\section{Call for papers}

10th European Forum on Quality Improvement in Health Care

13-15 April 2005, ExCel, Docklands, London

For further information on how to submit your paper please go to:

http://www.quality.bmipg.com 